\title{
Eritrosit Dağılım Genişliği (RDW): Metastatik Kolorektal Kanserde Prognoz Belirleyici Olarak Kullanımı ${ }^{*}$
}

\author{
Red Blood Cell Distribution Width (RDW): Useful Predictor for Treatment Response in Metastatic
}

Colorectal Cancer

\author{
Kadir Eseri, Emel Sezerii, Vehbi Erçolak ${ }^{\mathrm{iii}}$ \\ 'Araş.Gör.Uz.Dr., Mersin Üniversitesi İç Hastalıkları Anabilim Dalı Tıbbi Onkoloji Bölümü, https://orcid.org/0000-0001-8666-6177 \\ iiProf.Dr., Mersin Üniversitesi İç Hastalıkları Anabilim Dalı Tıbbi Onkoloji Bölümü, https://orcid.org/0000-0001-9881-3533 \\ iiiDoç.Dr., Mersin Üniversitesi İç Hastalıkları Anabilim Dalı Tıbbi Onkoloji Bölümü, https://orcid.org/0000-0003-1014-1694
}

ÖZET

Giriş: RDW, eritrosit dağılım genişliği, dolaşımdaki eritrositlerin büyüklüğünün değişkenliğini yansıtan eritrosit anizositozun derecesinin ölçülmesi için yaygın olarak kullanılan bir laboratuvar parametresidir. Kanserin, hem bir neden, hem de kronik inflamasyonun bir sonucu olduğu yaygın bir şekilde kabul görmesine rağmen, RDW yükselmesi solid kanser aktivitesinin potansiyel bir biyobelirteci olarak şimdiye kadar çok fazla araştırılmamıştır. Bizim çalışmamız RDW elevasyonunun kolorektal kanser aktivitesinin bir biyobelirteci olarak potansiyel rolü olup olmadığını değerlendiren ilk sistematik çalışmadır.

Metod: Ocak 2008 ile ağustos 2018 arasındaki Mersin Üniversitesi Tıp Fakültesi Tıbbi Onkoloji Polikliniği'ne başvuran 121 metastatik kolorektal kanserli hastada retrospektif analiz yapıldı. Çalışmanın dışlama kriterleri; başka bir malignite öyküsü olması, gebelik, böbrek nakli, hematolojik hastalıklar, ciddi anemi, enfeksiyon veya inflamatuar hastalıklar, demir eksikliği tedavisi, yeni venöz tromboz (son 6 ayda), yeni kan transfüzyonu (son 3 ayda), kronik obstrüktif akciğer hastalığı, hepatit b veya c, kalp yetmezliği, aritmi, tedavi edilmemiş tiroid hastalığı ve bilinen ciddi karaciğer ve/veya böbrek hastalığı olması.

Bulgular: Metastatik kolorektal kanser hastasının ortalama RDW değeri 15.95 iken, normal popülasyonda 13.5 idi. RDW düzeyi, diğer yüksek progresyon riski ve düşük progresyon riski olan hastalarda aynıydı. Hastaların ortalama genel sağkalımı, RDW $\leq 15$ olanların 42.5 ay, RDW> 15 olanların 26.3 ay idi. İi grupta istatistiksel olarak anlamlı fark yoktur.

Tartışma: RDW, kolon kanserlerinde anemi oluşumundan önce artan bir parametre olarak dikkat çekmektedir. RDW standart tam kan sayımında bulunur, herhangi bir ek maliyet getirmez ve kolayca değerlendirilebilir. Bu nedenle RDW, diğer belirteçlerle birlikte, kolorektal kanser riskini ve ilerlemesini öngörmede yardımcı olabilir.

Anahtar Kelimeler: Kolorektal, kanser, prognoz

\section{ABSTRACT}

Introduction: Red cell distribution width (RDW) is a widely used labora-tory parameter for the quantification of the extent of eryth-rocyte anisocytosis, which reflects the variability of the size of the circulating erythrocytes. Despite the fact that cancer is widely accepted to both as a cause and as a result of chronic inflammation, RDW elevation has scarcely been investigated as a potential biomarker of solid cancer activity. Our study is the first systemat-ic one to evaluate whether RDW elevation may have a poten-tial role as a biomarker of colorectal cancer activity.

Method: A retrospective analysis was conducted in patients with primary diagnosed or recurrent metastatic disease between January 2008 and August 2017. The exclusion criteria of the study were the presence of medical history of other malignancy, pregnancy, kidney transplantation, hematological disorders, severe anemia, infectious or inflammatory disease, iron supplementation therapy, recent venous thrombosis (past 6 months), recent blood transfusion (past 3 months), chronic obstructive pulmonary disease, hepatitis B or C, heart failure, arrhythmia, untreated thyroid disease, and severe liver and/or renal insufficiency as described previously.

Results: The mean RDW value of the metastatic colorectal cancer patient was 15.95, compared with 13.5 in normal population. The RDW values were same in patients at the high risk of progression and low risk of progression. The median overall survivall at patients have RDW $\leq 15$ were 42.5 mounths, patients RDW $>15$ were 26.3. There is no statically difference in two groups.

Discussion: RDW is found in the standard complete blood count, it does not bring any extra costs and it can be easily evaluated, which strengthens the fact that it can used as a biomarker in the early detection of cancer. Based on the findings of the current study, we recommend that RDW, a very common, easy, and simple marker, should be considered for treatment planning and follow-up of colorectal cancer patients.

Key words: Colorektal, cancer, prognosis

*Lokman Hekim Dergisi, 2019;9 (1): 66-72

DOI: $10.31020 /$ mutftd.466992

e-ISSN: 1309-8004

Geliş Tarihi - Received: 3 Ekim 2018; Kabul Tarihi - Accepted: 26 Kasım 2018

Iletişim - Correspondence Author: Kadir Eser <drkadireser@gmail.com> 


\section{Giriş}

RDW, eritrosit dağılım genişliği, dolaşımdaki eritrositlerin büyüklüğünün değişkenliğini yansıtan eritrosit anizositozun derecesinin ölçülmesi için yaygın olarak kullanılan bir laboratuvar parametresidir. ${ }^{1}$

Kolorektal kanser günümüzde, dünyada ve ülkemizde yaygın olarak görülmektedir ve yüksek oranda mortalite ve morbiditeye neden olmaktadır. Bu oranın rutin tarama ve tanı kılavuzları ile azaltılabileceği öngörülmektedir ${ }^{2,3}$ ancak bu oran henüz istenilen seviyede değildir.

Kolorektal kanserler özellikle kanamaya normalden daha yatkındırlar. Bu demir deposunu azaltır ve demir eksikliği anemisine neden olur.

Daha önceleri, RDW'nin klinik kullanımı, mikrositik anemiye neden olan anemiler arasında, talasemi ve diğer hemoglobinopatilerden, demir eksikliği anemisini ayırt etmekle ile sınırlıydı. Ancak son zamanlardaki birçok yayında, RDW yükselmesi ile iskemik kalp hastalığı, akut ve kronik kalp yetmezliği, ateroskleroz, vasküler tıkayıcı hastalık, hipertansiyon, inflamatuar barsak hastalığının aktif durumu, romatoid artrit ve genel olarak progresif inflamasyona yol açan durumlarla ilişkilendirilmiştir. ${ }^{4-8}$ inflamasyon ve oksidatif stresin RDW'yi etkilediği birçok yayınla bildirilmiştir. ${ }^{7}$ Ayrıca, RDW'nin kanda dolaşan hepsidin, IL-6, TNF-alfa ve diğer sitokinlerdeki artışı da yansıttığı gösterilmiştir. ${ }^{10,11}$

Kanserin, hem bir neden, hem de kronik inflamasyonun bir sonucu olduğu yaygın bir şekilde kabul görmesine rağmen ${ }^{13,14}$, RDW yükselmesi solid kanser aktivitesinin potansiyel bir biyobelirteci olarak şimdiye kadar çok fazla araştırılmamıştır. ${ }^{12-16}$

Globocan 2018'e göre Türkiye'de Kolorektal kanser insidansı 210.537'dir. Bizim çalışmamız RDW elevasyonunun kolorektal kanser aktivitesinin bir biyobelirteci olarak potansiyel rolü olup olmadığını değerlendiren ilk sistematik çalışmadır. RDW ucuz ve kolay uygulanabilir olduğu için metastatik kolorektal kanser hastalarının prognozunu tahmin etmemize katkı sağlayabilirse RDW yüksek hastalara daha yoğun tedavi verme yaklaşımı göz önünde bulundurulabilir.

\section{YÖNTEM}

Ocak 2008 ile ağustos 2018 arasındaki metastatik kolorektal kanserli 121 hasta retrospektif analiz edildi. Çalışmaya Mersin Üniversitesi Tıbbi Onkoloji Kliniği'ne başvuran, dosyasına ulaşılabilen tüm metastatik kolorektal kanserli hastalar alındı. Çalışmanın dışlama kriterleri; başka bir malignite öyküsü olması, gebelik, böbrek nakli, hematolojik hastalıklar, ciddi anemi, enfeksiyon veya inflamatuar hastalıklar, demir eksikliği tedavisi, yeni venöz tromboz (son 6 ayda), yeni kan transfüzyonu (son 3 ayda), kronik obstrüktif akciğer hastalığı, hepatit b veya c, kalp yetmezliği, aritmi, tedavi edilmemiş tiroid hastalığı ve bilinen ciddi karaciğer ve/veya böbrek hastalığı olması ${ }^{(17)}$. Çalışmamız Mersin Üniversitesi Etik Kurulu tarafından onaylanmıştır. Tüm veriler; yaş, cinsiyet, toplam sağkalım, histoloji, evre (2017 AJCC TNM sınıflaması), tümör lokalizasyonu, RAS durumu üzerine yapılandırılmıştır.

121 hastanın venöz kan örnekleri, tanı konulmadan önceki 15 güne kadar, ve tanı sonrası 15 güne kadar olanlar değerlendirmeye alınmıştır. RDW değeri, hemoglobin, ortalama hücre volümü (MCV), platelet ve beyaz kan hücreleri (WBC), XN-1000 (Sysmex Corporation, Kobe, Japan) otomatik kan analiz cihazı tarafından çalışıldı. Mersin Üniversitesi Biyokimya Laboratuarı'nda normal RDW aralığı \%11-15 arasındadır.

İstatistiksel analiz için Statistica v.13.0 programı kullanıldı. Tüm parametreler normal dağıtıldı ve ortalama \pm S.D olarak yazıldı. Kategorik değişkenler sıklık olarak gösterildi. Sayılabilir değişkenler bağımsız örneklem t testi ile korele edilirken kategorik değişkenlerde ki-kare testi kullanıldı. $\mathrm{P}<0.05$ değeri anlamlı kabul edildi. RDW değeri kolon kanseri sağkalımını değerlendirirken Kaplan-Meier sağkalım eğrisi kullanıldı.

\section{BULGULAR}

121 Metastatik kolorektal kanser hastasının ortalama RDW değeri 15.95 iken, normal popülasyonda 13.5 idi (Tablo 1). 121 hastanın RDW düzeyi, diğer yüksek progresyon riski ve düşük progresyon riski olan hastalarda aynıydı (Tablo 2). 
Tablo 1. Hastaların Temel Karakteristikleri

\begin{tabular}{llllll}
\hline Değişkenler & RDW2 & Hemoglobin & CRP & Yaş & Sağkalım \\
\hline $\mathrm{N}$ & 121 & 105 & 104 & 121 & 121 \\
Ortalama & 15,955 & 11,9429 & 50,1801 & 60,23 & 26,4082 \\
Std. Sapma & 2,7873 & 1,65011 & 82,60043 & 11,429 & 20,08872 \\
Minimum & 12,3 & 8,30 & 0,97 & 27 & 0,33 \\
Maksimum & 28,9 & 16,20 & 592,50 & 88 & 97,22 \\
\hline
\end{tabular}

Tablo 2. RDW düzeyine göre progresyon kriterleri

\begin{tabular}{llll}
\hline Progresyon kriteri & $\mathbf{N}$ & RDW ortalama \pm SD & P \\
\hline Sağ kolon & 29 & $15,9 \pm 3,3$ & 0,866 \\
Sol kolon & 89 & $16,0 \pm 2,6$ & \\
\hline Mutant & 37 & $16,1 \pm 3,5$ & 0,788 \\
Wild & 72 & $15,9 \pm 2,4$ & \\
\hline 4A & 20 & $16,3 \pm 3,4$ & 0,593 \\
4B & 65 & $15,9 \pm 2,9$ & \\
4C & 34 & $15.6 \pm 2.1$ & \\
\hline
\end{tabular}

121 hastanın 29'u sağ kolon tümörü, 34'ü evre 4C, 35'i RAS mutanttır ve bu özelliği taşımayan hastalara göre daha riskli grubu oluşturuyorlardı. RDW quartillerine göre yüksek progresyon riski olan hastaların dağılımı Tablo 3'te gösterilmiştir. Sağ kolon tümörü olan 29 hastadan, 7 hasta (\%23) 1.quartil, 9 hasta (\%32) 2.quartil, 6 hasta (\%20) 3.quartil, 7 hasta (\%22) 4. quartil. Evre 4C olan 34 hastadan 8 hasta (\%25) 1.quartil, 11 hasta (\%39) 2.quartil, 7 hasta (\%24) 3.quartil, 8 hasta (\%26) 4.quartildir. RAS mutant olan 37 hastadan 9 hasta (\%32) 1.quartil, 12 hasta (\%46) 2.quartil, 6 hasta (\%22) 3.quartil, 10 hasta (\%35) 4.quartildir. Bilinen kötü progresyon faktörlerinde, hastaların RDW quartilleri açısından bir fark yoktur. Ancak hastaların ortalama genel sağkalımı, RDW $\leq 15$ olanların 42.5 ay, RDW $>15$ olanların 26.3 ay idi. íki grupta istatistiksel olarak anlamlı fark yoktur (Tablo 4). Bu verinin Kaplan meier eğrisi de Şekil 1'de gösterilmiştir.

Tablo 3. RDW'ye göre Yüksek Riskli Hastaların Dağılımı

\begin{tabular}{|c|c|c|c|c|c|c|c|}
\hline & & & \multicolumn{5}{|c|}{ rdw_quartiles } \\
\hline & & & I $(\leq 13,9)$ & II $(13,9-15)$ & III $(15,1-17,5)$ & IV $(\geq 17,6)$ & $\mathbf{P}$ \\
\hline \multirow{2}{*}{$\begin{array}{l}\text { Primer } \\
\text { tümör yeri }\end{array}$} & Sağ & Sayı & 7 & 9 & 6 & 7 & 0,764 \\
\hline & & Yüzde & 23,3 & 32,1 & 20,7 & 22,6 & \\
\hline \multirow[t]{2}{*}{ Evre } & $4 C$ & Sayı & 8 & 11 & 7 & 8 & 0,570 \\
\hline & & Yüzde & 25,8 & 39,3 & 24,1 & 26,7 & \\
\hline \multirow[t]{2}{*}{ RAS } & Mutant & Sayı & 9 & 12 & 6 & 10 & 0,326 \\
\hline & & Yüzde & 32,1 & 46,2 & 22,2 & 35,7 & \\
\hline
\end{tabular}

Ki-kare ile değerlendirildiğinde quartil risk grupları arasında istatistiksel olarak anlamlı fark yoktur. 
Tablo 4. RDW seviyesine göre sağkalım değerlendirilmesi

RDW

$<=15 \quad>15$

\begin{tabular}{lcc}
\hline Hasta sayısı & 60 & 61 \\
Ortalama sağkalım & 42,25 & 26,3 \\
\hline
\end{tabular}

Survival eğrileri karşılaştırılması (Logrank test)

\begin{tabular}{lcc} 
Son durum: gözlenen ex sayısı & 35,0 & 36,0 \\
Beklenen ex sayısı & 38,6 & 32,4 \\
Ki-kare & 0,7496 & \\
P & 0,3866 & \\
\hline
\end{tabular}

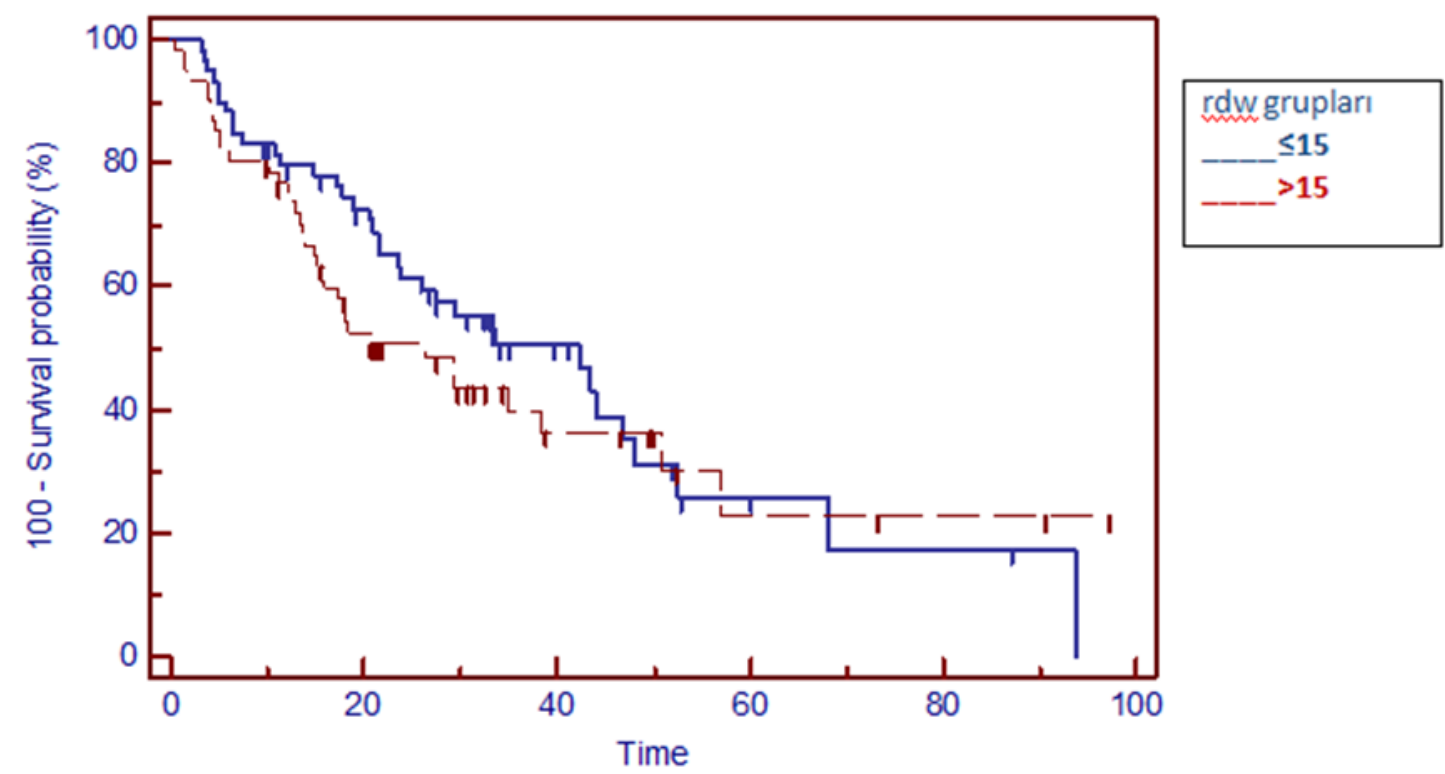

Risk grubu: $\leq 15$ sayiları

$60 \quad 39$

Risk grubu: $>15$ sayları

$61 \quad 29$

299

$15 \quad 4$

2

0

$\begin{array}{llll}3 & 2 & 1\end{array}$

Şekil 1. Kaplan-Meier sağkalım eğrisi

\section{TARTIŞMA}

Biz bu çalışmada ucuz ve kolay olduğu, standart tam kan sayımında bulunduğu, demir depoları yükseltilmediği veya anemi gelişmeden önce bakıldığında yüksek bulunduğu için kolorektal kanserde RDW düzeyi değişikliklerini araştırdık.

RDW tam kan sayımında bulunan, kanda eritrositlerdeki anizositozun belirleyicisi olan bir parametredir. Son zamanlarda RDW düzeyinin, romatoid artrit ve inflamatuar barsak hastalığında kardiyovasküler morbidite ve mortalite artışında, kronik ve aktif inflamasyon artışında yükseldiği gösterilmiştir. ${ }^{4-6,18}$ RDW, artmış oksidatif stresin erken habercisidir. RDW'nin demir mobilizasyonu bozukluğunda ve demir eksikliği anemisinde, CRP, IL-6, TNF a gibi inflamasyon belirteçleri ile korele olarak yükseldiği gösterilmiştir. ${ }^{6,19}$ Lippi ve arkadaşlarının yaptığı geniş ölçekli 3845 kişiyi kapsayan kohort çalışması, RDW artışının inflamasyonda sedimentasyon ve CRP ile korele olarak arttı̆̆ını göstermiştir. 
RDW artışının bozulmuş kardiyometabolik fonksiyon ve aktif inflamasyonda arttığı birçok çalışmada gösterilmiş olmasına rağmen, solid tümörlerin inflamasyonu tetiklediğini gösteren çalışmalar sınırlıdır. Sadece 2 çalışma RDW düzeyinin kolorektal kanserli hastalarda anemiyi erken teşhis etmede ek bir parametre olarak kullanılabileceğini gösterdi. ${ }^{15,16} \mathrm{Ek}$ olarak, Beyazıt ve arkadaşları ${ }^{20}$ artmış RDW düzeyi \%14.8 cut-off değeri alındığında \%72 sensitivite ve \%69 spesifite ile malign-benign biliyer tıkanıklık ayrımını yapmada faydalı olabileceğini yayınlamışlardır. Benzer olarak, memedeki benign ve malign lezyonları karşılaştıran Seretis ve arkadaşları ${ }^{9}$, RDW düzeyinin malign lezyonlarda arttığını gösterdi ancak hasta sayısı yetersizliğinden dolayı bir cutt-off düzeyi vermenin mümkün olmayacağını belirtti.

Anemi gelişmeden bile RDW yüksekliği olduğunda kolorektal kanserden şüphelenilmelidir. Bizim çalışmamızda RDW değeri yüksek olan metastatik kolon kanserinde prognoz, RDW değeri düşük olan gruba göre daha kötüdür. Ancak hemoglobin düzeyleri iki grupta da benzerdir.

İnflamasyonun, solid tümörlerin progresyonunda rol oynadığı gösterilmiştir, ancak agresif hastalığın artmış inflamasyona neden olup olmadığı veya inflamasyonun agresif hastalıktan kaynaklanıp kaynaklanmadığı belirsizdir. ${ }^{21,22}$ inflamasyon skoru hem kanser hem de kardiyovasküler hastalık mortalitesini öngörür. ${ }^{23}$ Kanserde, sadece ESR progresyonun bir göstergesi olarak incelenmiştir. ${ }^{24-35}$

Çalışmamızda daha yüksek bir RDW artmış bir progresyon riski ile ilişkili iken, düşük RDW değeri düşük bir progresyon riski ile ilişkilidir. Ayrıca, yüksek progresyon riskine sahip kolorektal kanser hastalarının RDW değerleri diğer kolorektal kanser hastaları ile benzerdir, fakat hastalarda RDW $\leq 15$ olanlar 42,25 ay, >15 RDW olanlar 26,3 aylık sağkalıma sahiptir. Bu oranlar her ne kadar istatistiksel olarak anlamlılığa ulaşmasa da yüksek bir sağkalım farkı vardır. Bu fark hasta sayısının azlığından kaynaklanabilir.

Bizim çalışmamız, kolorektal kanser hastalarında RDW değerlerinin normal popülasyona göre daha yüksek gözlemlenmesi ve kolorektal kanser oranı ile RDW değerleri arasındaki korelasyon, kolorektal kanserin progresyonunun öngörülmesi için daha yüksek RDW değerlerinin diğer parametrelerle birlikte kullanılabileceğini düşündürmektedir.

Ayrıca, RDW değerleri hasta takiplerini ve tedavilerini planlamaya yardımcı olacak rehberlik sağlayabilir. Hastalar, yüksek RDW değerlerine sahipse, genel sağkalımı azalmıştır. Progresyon riskinin ve RDW değerlerinin paralel olarak kademeli olarak artması gerçeği, RDW değeri yüksek olan hastaların kolorektal kanser progresyon riskinde artış olduğunu düşündürmektedir.

$\mathrm{Bu}$ çalışma, RDW değerlerinin ve diğer parametrelerin kullanımının kolorektal kanser sonuçlarını öngörmede yararlı olabileceğini düşündürmektedir. Bu, yüksek RDW değerleri olan kolorektal kanser hastalarının daha dikkatli takip ve tedavi planlaması için düşünülmesini gerektirir.

Sonuç olarak, RDW, kolon kanserlerinde anemi oluşumundan önce artan bir parametre olarak dikkat çekmektedir. RDW standart tam kan sayımında bulunur, herhangi bir ek maliyet getirmez ve kolayca değerlendirilebilir, bu da kanserin erken tespiti için biyobelirteç olarak kullanılabileceği tezini güçlendirir. Bu çalışmanın bulgularına dayanarak, kolorektal kanser hastalarının tedavi planlaması ve takibi için çok yaygın, kolay ve basit bir belirteç olan RDW'nin göz önünde bulundurulmasını tavsiye ediyoruz. RDW, diğer belirteçlerle birlikte, kolorektal kanser riskini ve ilerlemesini öngörmede yardımcı olabilir. İnflamasyonun bir göstergesi olan RDW'nin, kolorektal kanserin ilerlemesini ve agresifliğini öngören diğer parametrelerden bağımsız olarak, inflamatuar kaskadın kanser agresifliği ve ilerlemesi ile potansiyel ilişkisini gösterdiğini belirtiyoruz. Bununla birlikte, bu konuda daha fazla sayıda hasta içeren prospektif çalışmalara gereksinim vardır.

\section{KAYNAKLAR}

1.Forhecz Z, et al. Red cell distribution width in heart failure: prediction of clinical events and relationship with markers of ineffective erythropoiesis, inflammation, renal function, and nutritional state. Am Heart J 2009;158(4):659-666.

2. Rex DK, et al. Colorectal prevention 2000: screening recommendations of the American college of gastroenterology. Am J Gastroenterol 2000;95:868-77.

3. Winawer $\mathrm{S}$, et al. Colorectal cancer screening and surveillance: clinical guidelines and rationale-update based on new evidence. Gastroenterology 2003;124:544-60. 
4.Gunebakmaz O, et al. Red Blood Cell Distribution Width in 'Non-Dippers' versus 'Dippers'. Cardiology 2012;123(3):154-159.

5. Nishizaki Y, et al. Red blood cell distribution width as an effective tool for detecting fatal heart failure in super-elderly patients. Intern Med 2012;51(17):2271-2276.

6.Karabulut A, Uzunlar B. Correlation between red cell distribution width and coronary ectasia in the acute myocardial infarction. Clin Appl Thromb Hemost 2012;18(5):551-552.

7.Yesil A, ve ark. Red cell distribution width: a novel marker of activity in inflammatory bowel disease. Gut Liver 2011;5(4):460-467.

8.Lee WS, Kim TY. Relation between red blood cell distribution width and inflammatory biomarkers in rheumatoid arthritis. Arch Pathol Lab Med 2010;134(4):505- 506.

9. Patel KV, et al. Red cell distribution width and mortality in older adults: a meta-analysis. J Gerontol A Biol Sci Med Sci 2009;65: 258-65

10. Rhodes $\mathrm{CJ}$, et al. Iron deficiency and raised hepcidin in idiopathic pulmonary arterial hypertension: clinical prevalence, outcomes, and mechanistic insights. J Am Coll Cardiol 2011;58:300-9.

11. Seretis $C$, et al. Is red cell distribution width a novel biomarker of breast cancer activity? data from a pilot study. J Clin Med Res 2013;5:121-6.

12. Baicus $C$, et al. Utility of routine hematological and inflammation parameters for the diagnosis of cancer in involuntary weight loss. J Investig Med 2011;59(6):951-955.

13. Beyazit $Y$, et al. Can red cell distribution width help to discriminate benign from malignant biliary obstruction? A retrospective single center analysis. Hepatogastroenterology 2012;59(117):1469-1473.

14. Ozkalemkas $\mathrm{F}$, et al. The bone marrow aspirate and biopsy in the diagnosis of unsuspected nonhematologic malignancy: a clinical study of 19 cases. BMC Cancer 2005;5:144.

15. Spell DW, et al. The value of a complete blood count in predicting cancer of the colon. Cancer Detect Prev 2004;28(1):37-42.

16. Speights VO, et al. Complete blood count indices in colorectal carcinoma. Arch Pathol Lab Med 1992;116(3):258-260.

17. P.Qing, et al., "Evaluation of red blood cell distribution width in patientswith cardiac syndromeX," Disease Markers, vol. 34 , no. 5, pp. 333-339, 2013.

18. Albayrak S, et al. Red cell distribution width as a predictor of prostate cancer progression. Asian Pac J Cancer Prev 2014;15: 7781-4.

19. Agarval S. Red cell distribution width, inflammatory markers and cardiorespiratory fitness: Results from the National Health and Nutrition Examination Survey. Indian Heart J 2012;64:380-7.

20. Beyazit $Y$, et al. Can red cell distribution width help to discriminate benign from malignant biliary obstruc-tion? A retrospective single center analysis. Hepatogastroenterology. 2012;59:1469-73.

21. Kazma R, et al. Association of the Innate Immunity and Inflammation Pathway with Advanced Prostate Cancer Risk. Plos One $2012 ; 7$.

22. Klink JC, et al. Intratumoral inflammation is associated with more aggressive prostate cancer. World J Urol 2013;31:1497-503.

23. Godsland IF, North BV, Johnston DG. Simple indices of inflammation as predictors of death from cancer or cardiovascular disease in a prospective cohort after two decades of follow-up. Qjm-an Int J Med 2011;104:387-94.

24. Borre M, Nerstrom B, Overgaard J. Erythrocyte sedimentation rate-a predictor of malignant potential in early prostate cancer. Acta Oncol 1997;36:689-94.

25. Cakal B, et al. Red cell distribution width for assessment of activity of inflammatory bowel disease. Digestive Diseases and Sciences 2009;54:842-7.

26. Celikbilek A, et al. Red cell distribution width in migraine. Int J Lab Hematol 2013;35:620-8.

27. Cheng I, et al. Prostatitis, sexually transmitted diseases, and prostate cancer: the California men's health study. PLoS One 2010;5: 8736 .

28. Cho $\mathrm{H}$, et al. Pre-treatment neutrophil to lymphocyte ratio is elevated in epithelial ovarian cancer and predicts survival after treatment. Cancer Immunol Immunother 2009;58:15-23.

29. Cho H, Kim JH. Multiplication of neutrophil and monocyte counts (MNM) as an easily obtainable tumour marker for cervical cancer. Biomarkers 2009;14:161-70.

30. Cihan YB, Arslan A, Ergul MA. Subtypes of white blood cells in patients with prostate cancer or benign prostatic hyperplasia and healthy individuals. Asian Pac J Cancer Prev 2013;14:4779-83.

31. Dennis LK, Dawson DV. Meta-analysis of measures of sexual activity and prostate cancer. Epidemiology 2002;13:72-9. 
32. Kaptoge S, et al. C-reactive protein concentration and risk of coronary heart disease, stroke, and mortality: an individual participant meta-analysis. Lancet 2010;375:132-40.

33. Felker GM, et al. Red cell distribution width as a novel prognostic marker in heart failuredata from the charm program and the duke databank. J Am College Cardiol 2007;50:40-7.

34. Ferronika P, et al. p63 cytoplasmic aberrance is associated with high prostate cancer stem cell expression. Asian Pac J Cancer Prev 2012;13:1943-8.

35. Fujita K, et al. Low serum neutrophil count predicts a positive prostate biopsy. Prostate Cancer Prostatic Dis 2012;15:386-90. 